\title{
Multiple-Fault Detection Methodology Based on Vibration and Current Analysis Applied to Bearings in Induction Motors and Gearboxes on the Kinematic Chain
}

\author{
Juan Jose Saucedo-Dorantes, ${ }^{1}$ Miguel Delgado-Prieto, ${ }^{2}$ Juan Antonio Ortega-Redondo, ${ }^{2}$ \\ Roque Alfredo Osornio-Rios, ${ }^{1}$ and Rene de Jesus Romero-Troncoso ${ }^{3}$ \\ ${ }^{1}$ CA Mecatronica, Facultad de Ingenieria, Campus San Juan del Rio, Universidad Autónoma de Querétaro, Rio Moctezuma 249, \\ Colonia San Cayetano, 76807 San Juan del Rio, QRO, Mexico \\ ${ }^{2}$ Technical University of Catalonia (UPC), Department of Electronic Engineering, MCIA Research Center, \\ Rambla San Nebridi No. 22, Gaia Research Building, 08222 Terrassa, Spain \\ ${ }^{3}$ CA Procesamiento Digital de Señales, CA Telematica, Division de Ingenierias, Campus Irapuato-Salamanca, \\ Universidad de Guanajuato, Carretera Salamanca-Valle km $3.5+1.8$, Comunidad de Palo Blanco, 36700 Salamanca, GTO, Mexico
}

Correspondence should be addressed to Rene de Jesus Romero-Troncoso; troncoso@hspdigital.org

Received 12 November 2015; Accepted 23 February 2016

Academic Editor: Konstantinos N. Gyftakis

Copyright (C) 2016 Juan Jose Saucedo-Dorantes et al. This is an open access article distributed under the Creative Commons Attribution License, which permits unrestricted use, distribution, and reproduction in any medium, provided the original work is properly cited.

Gearboxes and induction motors are important components in industrial applications and their monitoring condition is critical in the industrial sector so as to reduce costs and maintenance downtimes. There are several techniques associated with the fault diagnosis in rotating machinery; however, vibration and stator currents analysis are commonly used due to their proven reliability. Indeed, vibration and current analysis provide fault condition information by means of the fault-related spectral component identification. This work presents a methodology based on vibration and current analysis for the diagnosis of wear in a gearbox and the detection of bearing defect in an induction motor both linked to the same kinematic chain; besides, the location of the fault-related components for analysis is supported by the corresponding theoretical models. The theoretical models are based on calculation of characteristic gearbox and bearings fault frequencies, in order to locate the spectral components of the faults. In this work, the influence of vibrations over the system is observed by performing motor current signal analysis to detect the presence of faults. The obtained results show the feasibility of detecting multiple faults in a kinematic chain, making the proposed methodology suitable to be used in the application of industrial machinery diagnosis.

\section{Introduction}

Condition monitoring and fault diagnosis in rotating machinery are important topics in industrial applications. The most common rotating machines are induction motors and the associated kinematic chains which include gearboxes and are widespread in different applications. This topic has attracted the attention of many researchers over the last few years $[1,2]$, emphasizing the necessity of health monitoring and maintenance procedures in manufacturing operations in order to ensure equipment availability, product quality, ontime deliveries, and plant safety [3-6]. In many applications, induction motors are connected to gearboxes $[7,8]$, and it is important to identify faulty conditions at an early stage while these elements are under operation along with the related kinematic chain. Although it has been shown that about $41 \%$ of the induction motor faults are due to bearing defects, this condition does not usually cause an immediate breakdown. In gearboxes, however, the possibility of gear fault appearing is lower, around $26 \%$, but an early stage fault, as uniform wear, may cause severe consequences $[9,10]$. Indeed, induction motors, gearboxes, and bearings represent critical components in the kinematic chain, and the presence of incipient faults may lead to unexpected interruptions 
and nonproper operation in industrial processes [11-13]. Thus, the necessity of health monitoring schemes to consider multiple-fault sources is generating new investigations and methods based upon the condition monitoring field.

Condition monitoring applied to rotating machinery can be based on different physical magnitudes such as vibration, stator currents, and sound signals. Nevertheless, vibration based monitoring and motor current signature analysis represent the most accepted strategies. More than $82 \%$ of fault diagnosis methodologies have been done using vibration analysis $[9,14,15]$. Vibration analysis for monitoring rotating machines has been used during the last decades because of the dynamic forces within a rotating machine that produce a vibration force and the vibration pattern changes when a fault appears, even at an early stage. Thus, vibration analysis is a useful and reliable tool to assess the machinery condition [16-18]. Stator current based analysis has been also adopted by many researchers for condition monitoring in electrical rotating machines due to its advantages of being noninvasive and easy to use. Although vibration analysis is better suited for mechanical fault identification, the mechanical fault effects can also be detected by means of current analysis since the induction motor current consumption is modified by the mechanical efforts and vibrational modes in rotating machines [19-21]. Sound analysis is related to the use of acoustic emission signals; it has been applied during the last year in many research works and, similar to current analysis, it represents a noninvasive technique. Yet, due to the nature of the acoustic emission signals, the related processing is more complex, and the required sensors are more expensive than acceleration and Hall effect sensors. Therefore, mechanical faults detection can be addressed by means of vibration and current analysis, offering high reliability and moderate costs. In this regard, the fusion of both vibration and current analysis is expected to increase the multifault occurrence detection capabilities [22-25].

Many methodologies based on vibration analysis have been used for identifying specific faults in both induction motors and gearboxes. The most common analysis techniques are based on statistical time domain, frequency domain, and the joint time-frequency domain. The time domain analysis involves the extraction of specific features such as Root Mean Square (RMS), skewness, kurtosis, and crest factor. The best known methods regarding frequency domain and time-frequency domain analysis are the Fast Fourier Transform (FFT), Short-Time Fourier Transform (STFT), Continuous Wavelet Transform (CWT), and Hilbert Huang Transform (HHT) [26, 27]. In general, the specific technique is chosen according to the application. For instance, FFT is preferred when the analysis is performed over stationary signals having a low computational cost. Other methods are better suited when the signal is nonstationary. Regrettably, most of the condition monitoring techniques for early fault detection focus on the detection of single specific faults. For instance, in [28], a single fault in bearings is diagnosed and detected using HHT and Support Vector Machines (SVM) applied to the vibration signal. In [29] an incipient bearing fault classification was done using a vibration spectrum imaging under low signal to noise ratio conditions. Also, some researchers are looking for the development of systems including monitoring and diagnosis capabilities; in this case, in [30], the authors developed a system for vibration signal monitoring in a rotating machine; with this system a classification between bearing defect and eccentricity was found. Other kinds of signal processing methods can be used; in [31] a method where the Kurtogram is obtained for a specific frequency band and the bearing condition is proposed. The detection of specific mechanical faults can be conducted by the use of different signals to those of vibration; bearing defect is one of the most common faults detected by performing a current signal processing; for instance, in [12] a method based on current analysis by performing also a Kurtogram extraction for detecting bearing faults in induction motors is proposed. The interest in studying the effects caused by bearing defects has increased during the last years, even new research and comparisons between vibrational and current signals have been carried out. In this sense, the works presented in $[14,18]$ proposed some techniques in which the bearing defect is detected and the vibration effects are reflected in current signals; their studies were focused on the relation between mechanical and electrical frequencies.

Unfortunately, most of the researches in condition monitoring around gearboxes are focused on the detection of discrete faults as broken teeth, and few works are related to the diagnosis and the identification of early stage faults as uniform wear. Li et al. [32] proposed a method for detecting advanced faults in gear based systems; the method was based on the vibration analysis using the HHT and the empirical mode decomposition. Nowadays, common applications are associated with gearboxes in their kinematic chain; for this reason condition monitoring in gearboxes is a current and important topic [33-35]. In this case, in [16], a spectral analysis is performed to monitor the amplitude increasing and the demodulation along the meshing frequency; these effects were produced by the pitting on the surface of the gear teeth studied. In [36] the gear condition is established using a frequency analysis applied to vibration signals; besides, a demodulation effect due to gear tooth damage is observed. Because a kinematic chain is composed of several elements, it may be possible that different faults caused by different elements would appear. However, there are just a few research works dealing with multiple faults occurrence and even fewer developments considering incipient stages in such multifault scenarios, as, for instance, the appearance of an incipient stage fault in a gearbox based on a uniform gear wear and its combination with a bearing defect. Some specific cases when multiple faults are analyzed exist because the studied faults are too severe; for instance, in [25], a technique based on vibration analysis for fault detection in a mechanical system is proposed; the considered faults were gear and bearing faults, but both are in an advanced fault stage.

It is possible to identify some lack of accuracy in a few of the aforementioned researches because in most of them a single fault in a specific element is studied; yet, in the presence of multiple faults, the use of different approaches is required to improve, or at least to maintain, the diagnosis capabilities. Furthermore, the use of techniques such as vibration and 
current analysis represents the best option in multiple-fault detection because each technique has the ability of detecting a specific fault. Besides, with the monitoring of the most significant physical magnitudes in a specific process, it is possible to ensure its efficiency because any change presented in the signals patterns can be related to the fault appearance; these provide the motivation for conducting the present research. Furthermore, the combination of incipient faults with other faults in the kinematic chain has not been sufficiently studied. The novelty of this work lies in the proposal of a methodology based on vibration and current analysis for the diagnosis of uniform wear in a gearbox and the detection of bearing defect in an induction motor, both linked to the same kinematic chain.

Because there are not established schemes around the considered multifault scenario, the contribution of this work is the proposal and validation of a methodology for multiple faults identification in a kinematic chain and the knowhow of both uniform wear in a gearbox and induction motor bearings in a faulty stage, which produce changes along the kinematic chain behavior such as speed variations, current consumptions in the induction motor, the addition of nonlinear frequency components, or the transmission of vibration modes. The vibration analysis is done by means of a spectral analysis; part of the proposed methodology is based on extracting some characteristic frequency components from a theoretical model. The analysis is based on the amplitude increase and the spectral modulation in order to quantify the uniform wear level in the gearbox and the bearing defect presence. Similarly, the current analysis is confronted by the motor current signal spectral analysis in order to identify and corroborate the presence of the faults while observing the vibrational effects. Thus, the presence of multiple faults can be detected by using two different signatures in a condition monitoring process; the use of different signals makes the methodology more reliable in the diagnosis and detection of multiple faults. The obtained results from the proposed methodology show that it is possible to identify the frequency components associated with the studied faults and their mixing.

\section{Theoretical Background}

2.1. Vibration in Rotating Machinery with Gears. The mechanical vibrations in the study of rotating machinery with gears are inherent to its operation because these are generated by the backlash or the excitation of the dynamic forces induced when the gear teeth enter in contact; consequently, at higher backlash, the vibration amplitude is higher. Moreover, variations at speed and load also contribute to vibrations in systems with gears, when the gear teeth enter in contact producing an impact frequency called mesh frequency $\left(f_{m}\right)$ and it is the main frequency at which gearing induces vibrations and it is given by

$$
f_{m}=N \cdot f_{r},
$$

where $N$ is the teeth number and $f_{r}$ is the rotational frequency of the input or output shaft to analyze. It is useful to note that several gear meshing frequencies are present in a complex gear train [36-38].

The most common gear fault is a discrete gear tooth irregularity such as a broken or chipped tooth. With a single discrete fault, the increase in levels of noise and vibrations can be expected at the shaft rotational frequency and its corresponding associated harmonics. These narrowband peaks are in addition to the various gear meshing frequencies and their associated harmonics. Also, discrete faults tend to produce low-level, flat, sideband spectra around the mesh frequency and its harmonics.

For gearboxes in good condition, the vibration spectra commonly show the input and output shaft frequencies as well as the mesh frequency with sideband frequencies $\left(f_{\text {sideband }}\right)(2)$ around the mesh frequency and its corresponding harmonics. A theoretical spectrum vibration for a healthy gearbox is shown in Figure 1(a):

$$
f_{\text {sideband }}=f_{m} \pm f_{r} \text {. }
$$

Such $f_{\text {sideband }}$ typically arises from the modulation of the tooth meshing waveform by the gear rotational frequency. When the teeth are in good condition and the gears are concentric, the amplitude of $f_{m}$ and $f_{\text {sideband }}$ and its harmonics are low. On the other hand, an increase of amplitude in $f_{m}$ and $f_{\text {sideband }}$ and its harmonics is associated with uniform wear as shown in Figure 1(b); the increase of these frequency components and their associated harmonics is typical criterion for fault detection. Given that for a pair of gears, $f_{m}$ is the same, then the information contained in $f_{\text {sideband }}$ allows knowing which one is the worn gear; this is determined since each gear has different $f_{r}$.

Gearboxes are considered as a complex system in rotating machines; this consideration is due to the appearance of nonlinear vibration and the addition of unexpected frequency components, along with the combination of higher operating speeds [38]. Additionally, the modulation and the appearance of nonlinear frequencies in gearboxes also depend on and can be generated by the material used in their construction and the linked elements inside the gearbox like bearings. In this sense, the existence of theoretical mechanical models with actual approaches may lead to understanding the behavior of these phenomena in gearbox systems [39].

2.2. Bearing Defect. In machine condition monitoring, much attention is generally given to bearing condition because it is the most common component; the rotational movement in bearing elements generates vibrational excitation at a series of discrete frequencies. Some researches give a review of the causes and expected frequencies of vibration due to bearing defects $[11,17,18]$. The characteristic frequencies regarding bearing defect are theoretically well known; these frequencies are mainly computed from the rotational frequency and the bearing geometry. These characteristic frequencies are the inner and outer race elements pass frequencies $\left(f_{\mathrm{BPIF}}, f_{\mathrm{BPOF}}\right)$, 


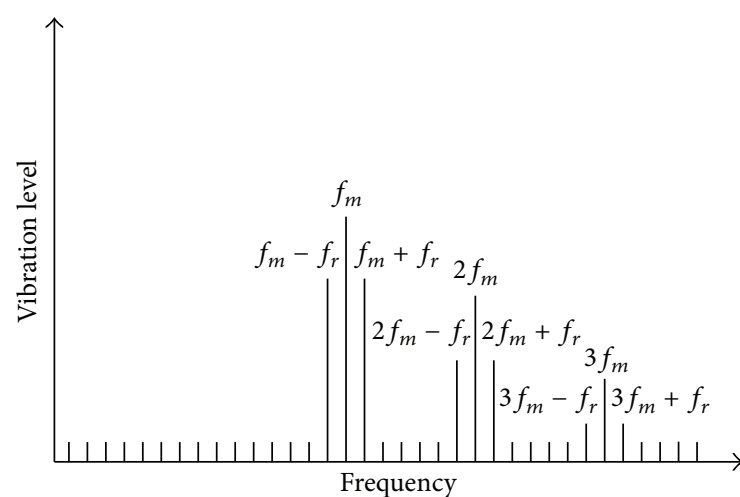

(a)

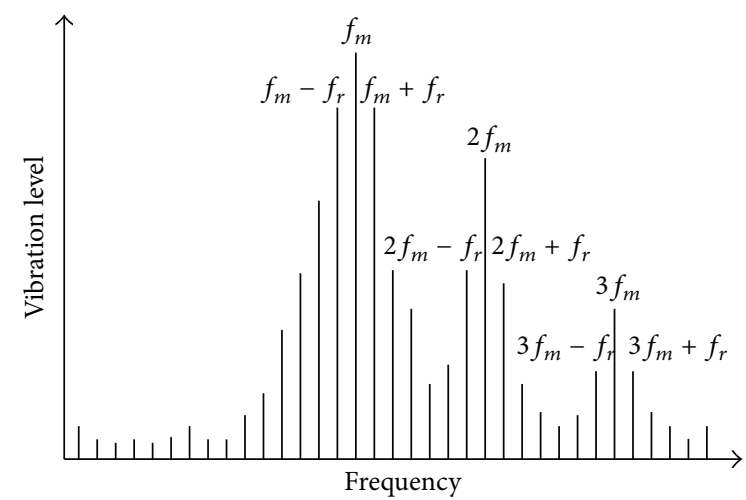

(b)

Figure 1: Typical vibration spectrum of a gearbox in (a) healthy condition and (b) with uniform wear.

the frequency of rotation for the cage $\left(f_{\mathrm{FTF}}\right)$, and rolling element spin frequency $\left(f_{\mathrm{BSF}}\right)$. Their corresponding expressions are as follows:

$$
\begin{aligned}
f_{\mathrm{BPIF}} & =\frac{f_{r}}{2} N_{b}\left(1+\frac{D_{B}}{D_{C}} \cos \theta\right), \\
f_{\mathrm{BPOF}} & =\frac{f_{r}}{2} N_{b}\left(1-\frac{D_{B}}{D_{\mathrm{C}}} \cos \theta\right), \\
f_{\mathrm{FTF}} & =\frac{f_{r}}{2}\left(1-\frac{D_{B}}{D_{\mathrm{C}}} \cos \theta\right), \\
f_{\mathrm{BSF}} & =\frac{D_{\mathrm{C}}}{2 D_{B}} f_{r}\left(1-\left(\frac{D_{B}}{D_{\mathrm{C}}}\right)^{2}(\cos \theta)^{2}\right),
\end{aligned}
$$

where $f_{r}$ is the rotational frequency at which the inner raceway rotates, $D_{C}$ is the cage diameter measured from a ball center to the opposite ball center, $D_{B}$ is the ball diameter, $N_{b}$ is the number of balls, and $\theta$ is the contact angle between the bearing surfaces.

The excitation of the previous frequencies can be used in bearing fault detection because these frequencies would appear in the vibration spectrum. The primary source of noise and vibration in rotating machinery with bearing defects is due to the mechanical impact produced by the rolling elements over the bearing races. When the bearing defect is located in the outer race it will cause an impulse each time the rolling elements contact the defect; sometimes the modulation effect is present in the vibration signal; this phenomenon can be explained by different causes such as nonuniform load, flexural bearing modes, and vibrations induced by other elements in rotating machinery [17].

The vibration component effect on the current is modeled as a static eccentricity; in this case bearing faults generate stator currents at predictable frequencies related to the mechanical characteristic frequencies $\left(f_{\mathrm{BPIF}}, f_{\mathrm{BPOF}}, f_{\mathrm{FTF}}, f_{\mathrm{BSF}}\right)$ and electrical supply frequency $\left(f_{s}\right)$; for this study the following equation represents the link between vibration and current components [14]:

$$
f_{\mathrm{BE}}=f_{s} \pm k f_{\mathrm{BPOF}},
$$

where $k=1,2,3, \ldots$

\section{Methodology and Experimental Setup}

This section shows the proposed methodology and the description of the experimental setup for the diagnosis of wear in a gearbox and the detection of bearing defect in an induction motor; both faults are over the same kinematic chain.

3.1. Methodology. The flow chart of Figure 2 depicts the proposed methodology. This work is focused on the detection of different faults. First, the different studied conditions are defined as healthy, three levels of wear on the gearbox, the bearing defect, and the blending of each wear level with the bearing defect. These faults are artificially made, and the damaged elements are replaced in a specific kinematic chain for carrying out different experiments. Also, different rotating frequencies for each experiment are used in order to observe the speed dependencies for every studied fault.

Afterwards, vibration data are acquired from a triaxial accelerometer placed on the top of the gearbox. Besides, the motor current and the rotating speed are acquired from the Hall effect sensors and a digital encoder, respectively. In order to obtain the kinematic chain vibration, the motor current, and the rotational frequency, all the data are captured during the operation of the kinematic chain in each studied condition for all the different experiments executed. Then, the spectral analysis is performed consisting in applying a Hanning time window to the vibration and current signals to reduce the spectral leakage. The FFT and the Power Spectral Density (PSD) are then computed to get the vibration and current spectra to be analyzed.

After that, with the aim of locating a specific bandwidth to find the spectral frequency components that are related to each studied condition, the theoretical frequencies are computed. Therefore, these values are obtained by replacing the speed acquired, the characteristics of the gearbox, and the bearing geometry in (1), (4), and (7). The computed frequencies are summarized in Table 1 . It is important to mention that these values correspond to approximations and are subjected to suffer variations (not greater than $3 \%$ of the expected value) due to the operating conditions. 


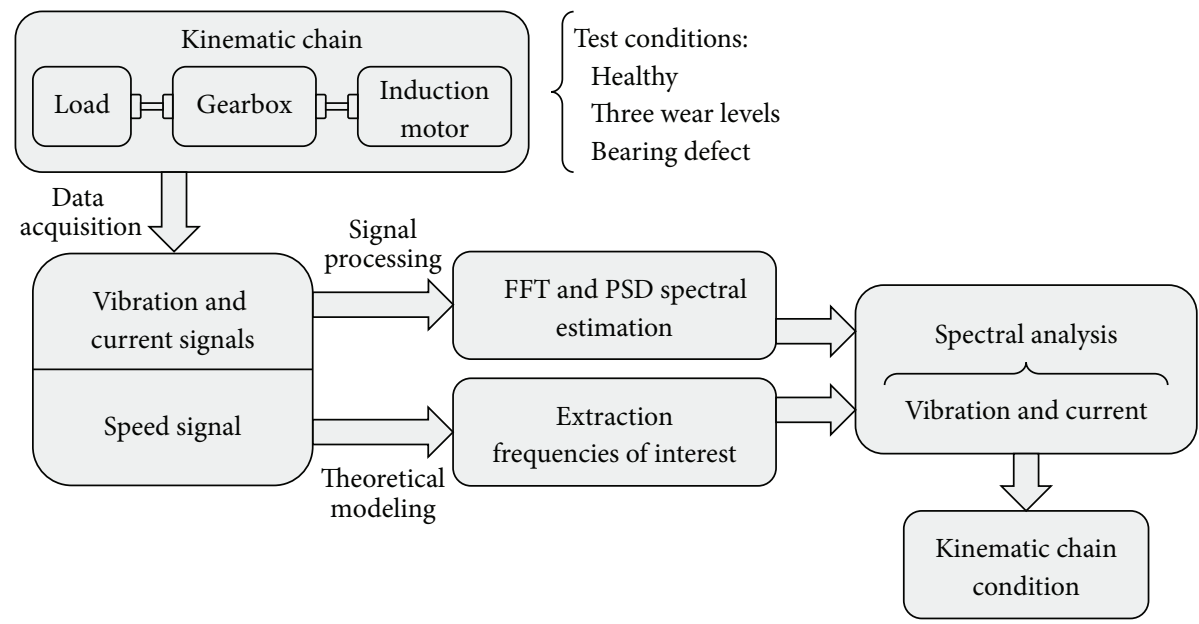

FIgURE 2: Flow chart of the proposed methodology.

TABLE 1: Computed frequencies of interest.

\begin{tabular}{lcccccc}
\hline Rotational & \multicolumn{6}{c}{ Frequencies of interest $(\mathrm{Hz})$} \\
speed $(\mathrm{rpm})$ & $f_{m}$ & $2 f_{m}$ & $f_{\mathrm{BPOF}}$ & $2 f_{\mathrm{BPOF}}$ & $f_{\mathrm{BE}}$ & $f_{r}$ \\
\hline 293.4 & 88.02 & 176.04 & 17.50 & 35 & 21.99 & 4.89 \\
889.28 & 266.79 & 533.58 & 53.06 & 106.12 & 67.88 & 14.82 \\
2984.4 & 895.32 & 1790.65 & 178.09 & 356.18 & 227.83 & 49.74 \\
\hline
\end{tabular}

Then, the frequencies of interest associated with the studied cases are located in both vibration and current spectra. For the purpose of quantifying the severity of the fault, a comparison in the amplitude increase between related frequencies in the healthy and faulty stage is performed. Finally, for each different experiment, the kinematic chain condition is given according to the proposed criteria of evaluation.

3.2. Test Bench. The test bench used for testing the kinematic chain with different faults and the acquisition system used to capture the vibration and current signals is shown in Figure 3. The test bench consists of a 1492-W, three-phase induction motor (WEG 00236ET3E145T-W22), with its rotational speed controlled through a variable frequency drive (VFD) (WEG CFW08), set to different frequencies. A 4:1 ratio gearbox (BALDOR GCF4X01AA) is used for testing the different levels of uniform wear studied in this work, and a DC generator (BALDOR CDP3604) is used as the mechanical load comprising around $20 \%$ of the nominal load. The vibration signals are acquired using a triaxial accelerometer (LIS3L02AS4), mounted on a board with the signal conditioning and antialias filtering, and the current signals are acquired by using a Hall effect sensor (L08P050D15), from Tamura Corporation. Two 12-bit 4-channel serial-output sampling analog-to-digital converters (ADS7841) are used on board of data acquisition system (DAS), with a sampling frequency of $3 \mathrm{kHz}$ for vibration signal acquisition and a sampling frequency of $4 \mathrm{kHz}$ for current signal acquisition, obtaining $60 \mathrm{kS}$ and $80 \mathrm{kS}$, respectively, during 20 seconds of the induction motor from start-up to steady state. The DAS is a proprietary low-cost design based on field programmable gate array technology (FPGA). The output rotational speed is captured using a digital encoder; the motor start-up is controlled by a relay in order to automatize the test run. All the aforementioned data are stored in a personal computer (PC) and analyzed under MATLAB, which is used for signal processing to compute the spectra of the vibration and current signals for each studied condition. The proposed method, implemented under MATLAB, consists of two Hanning filters so as to filter each of the acquired signatures; then, two 4096-point FFT are applied over the complete range of frequency for each signal and finally for the current signal the PSD is computed. These processing methods represent low computational cost and they are standard procedures that can be easily implemented in embedded systems for online operation, such as field programmable gate arrays. Some instances of the implementation of FFT and other standard signal processing methods can be found in [40,41].

3.3. Description of the Studied Faults. As aforementioned, wear in gears and bearing defect are the studied faults. The considered fault in gears is a uniform wear due to the nonexistence of reported scientific studies using vibration analysis in gradual faults monitoring like uniform wear. Three levels of worn gears, which have 72 teeth, are used in this work to analyze different vibration effects in the kinematic chain and validate the ability of the proposed methodology to distinguish different levels of wear on the gears. The three levels of wear are artificially made at the gear factory, and it was induced for all teeth in a uniform way. Figures $4(\mathrm{a})-4(\mathrm{~d})$ show the gears studied in this work: healthy and $25 \%, 50 \%$, and $75 \%$ of wear, respectively. As mentioned, the vibration characteristic-defect frequencies are calculated using the gearbox characteristics and the speed acquired in (1).

Regarding the bearing defect, an artificial damage is produced by drilling a hole with $1.191 \mathrm{~mm}$ of diameter on the bearing outer race using a tungsten drill bit. This fault 


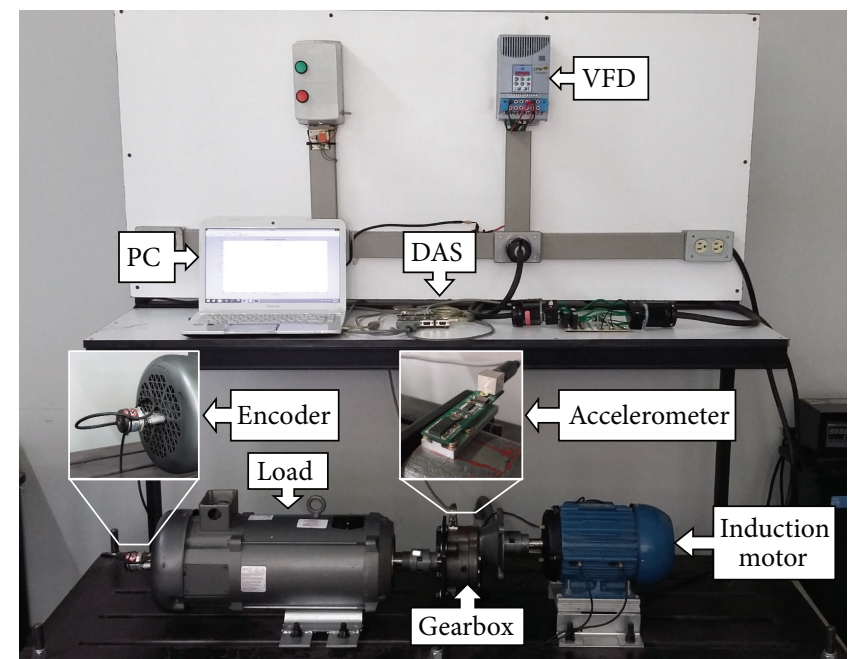

FIGURE 3: Test bench used for experimentation.

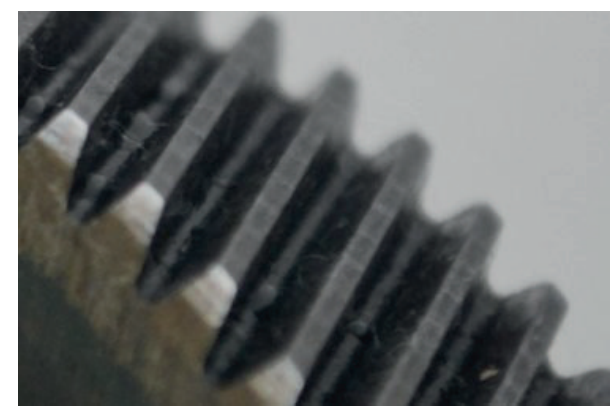

(a)

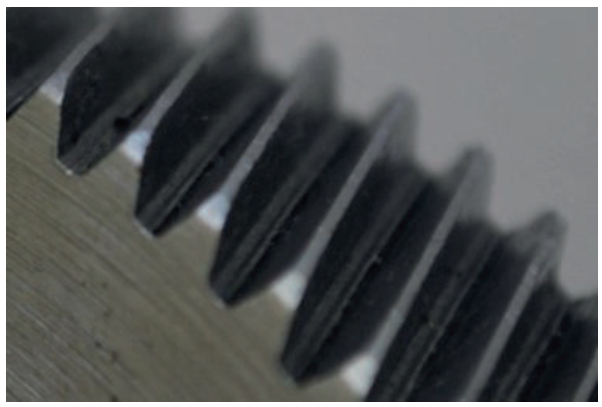

(c)

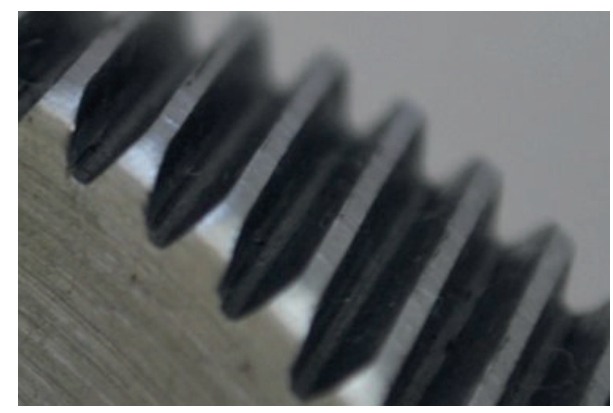

(b)

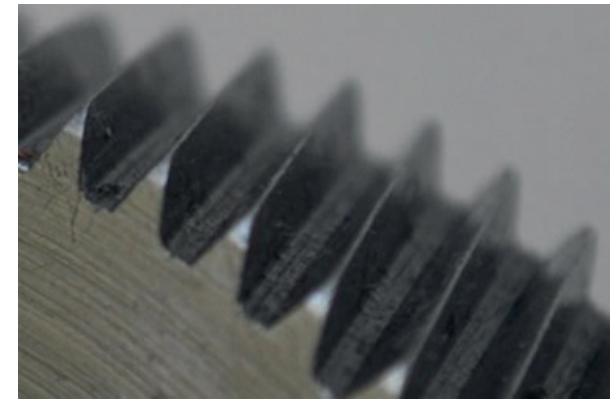

(d)

FIGURE 4: Treated gears: (a) healthy and (b) 25\%, (c) 50\%, and (d) $75 \%$ of wear.

has been used and reported in different studies [5, 11], and the artificial damaged bearing model 6205-2ZNR used in this experimentation is shown in Figure 5. Using (4) the vibration characteristic-defect frequency of the rolling element bearing outer race is calculated; then using $f_{\mathrm{BPOF}}$ into (7) the current characteristic-defect frequency related to the vibration defect is also calculated. The induction motor has different rotor frequencies; the test bearing has nine balls of $7.9 \mathrm{~mm}$ diameter and the cage diameter of the bearing is $39 \mathrm{~mm}$ with a contact angle $\theta=0^{\circ}$.

\section{Results and Discussion}

The results provided in this section are obtained by applying the proposed methodology. The experiments were carried out by replacing the healthy gear with one of the worn gears iteratively and combining each gear wear level with the bearing defect. As it has been mentioned, for each experiment, vibration, current, and speed signals are acquired. In this sense, the operational rotating frequency is computed through the speed signal given by the digital encoder. Although 


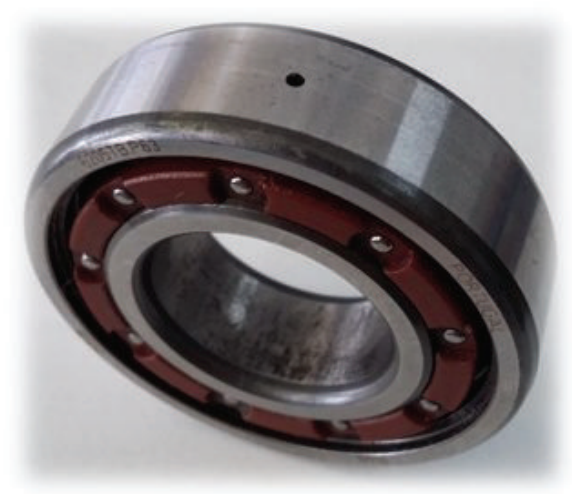

FIgURE 5: Outer race damaged bearing.

some specific frequencies such as $5 \mathrm{~Hz}, 15 \mathrm{~Hz}$, and $50 \mathrm{~Hz}$ are established in the VFD, the output operational frequency for each case is slightly below the set-point frequency because of the slip in the rotor, as it is shown in Table 1. The main purpose of the research is the vibration analysis and the current analysis of the fault-related components as calculated from the theoretical model. Then, the diagnosis in rotating machinery at different fault stages through signal processing is made. The nature of the considered faults implies generation of shock impulses along the kinematic chain, which means that time domain based vibration analysis is not suitable for detection. Thus, the acquired vibration data are analyzed with the FFT and the acquired motor current data are analyzed with the PSD. The FFT technique has some disadvantage in the analysis of signals when the characteristic frequencies of the system are nonstationary. The use of VFD to feed the motor implies that the system can operate at different supply frequencies. The FFT is suited for analyzing the signals from this system, as long as the operating frequency at the VFD is set and the steady state is reached because the system is stationary under these conditions. Yet, under these steady state operating conditions, if the mechanical load varies during the operations, the performance of the FFT method can be affected. For this study, the conditions are kept to avoid load variations during steady state operation.

Considering the vibration signal, the best results are obtained from the perpendicular plane to the shaft; this is due to the fact that treated faults tend to generate radial forces that are converted into vibration motion in this direction. Consequently, vibration spectra shown in Figure 6 correspond to the healthy stage and a $50 \%$ of uniform wear when the VFD is set to $15 \mathrm{~Hz}$. In these spectra it is possible to detect significant frequencies such as the rotational frequency $\left(f_{r}=14.65 \mathrm{~Hz}\right)$, the mesh frequency $\left(f_{m}=267.3 \mathrm{~Hz}\right)$, the ball pass outer race frequency $\left(f_{\mathrm{BPOF}}=52.73 \mathrm{~Hz}\right)$, and their corresponding second harmonic $\left(2 f_{m}=534.7 \mathrm{~Hz}, 2 f_{\mathrm{BPOF}}=104 \mathrm{~Hz}\right.$, and $4 f_{\mathrm{BPOF}}=208 \mathrm{~Hz}$ ). Figure 6(a) shows the spectrum for the healthy condition; in this spectrum the related frequencies are present with a low amplitude level; also the appearance of unexpected vibration components is present in the spectrum; specifically around the second harmonic in the $2 f_{m}$, the lateral sidebands are full of additional frequency components. On the other hand, Figure 6(b) shows the spectrum for the experiment with $50 \%$ of uniform wear; the frequency amplitude increases significantly in this case. As well as in the healthy stage, the addition of frequency components appears around $f_{m}$ and $2 f_{m}$, but in this spectrum these frequencies have higher amplitude than the additional components.

A relevant feature of both spectra is the appearance of the sideband frequencies, related to the rotating speed, near the mesh frequency and its harmonics. The amplitude increase in these regions allows the identification of the gearbox frequency and fault presence. Besides, bearing frequencies are present with lower amplitudes because the bearing vibration amplitude is lower in comparison with gearbox vibration amplitude; yet, the bearing-related frequencies appear in the spectrum.

Figure 7 shows some of the obtained spectra of the vibrational behavior when the healthy stage, $75 \%$ of wear, bearing defect, and their mixing are tested at $5 \mathrm{~Hz}$. For each of these vibration spectra it is possible to identify the fault-related frequency components, which are associated with the rotating frequency $\left(f_{r}=4.83 \mathrm{~Hz}\right)$, the mesh frequency $\left(f_{m}=87.89 \mathrm{~Hz}\right)$, the ball pass outer race frequency $\left(f_{\mathrm{BPOF}}=17.21 \mathrm{~Hz}\right)$, and their corresponding harmonics $\left(2 f_{m}=176.1 \mathrm{~Hz}, 3 f_{m}=264.8 \mathrm{~Hz}, 2 f_{\mathrm{BPOF}}=34.06 \mathrm{~Hz}\right.$, and $3 f_{\mathrm{BPOF}}=53.1 \mathrm{~Hz}$ ).

For the spectrum in the healthy condition shown in Figure 7(a) it is possible to notice that the fault-related frequencies have low amplitude in comparison with all of the others spectra, especially the gearbox frequencies. In the presence of the bearing fault when the gear is in a good condition as Figure 7(b) shows, the amplitudes of the frequencies remain on the same approximated level. However, the appearance of frequency components in both spectra is inevitable in the closest region to the mesh frequency sidebands and its harmonics.

On the other hand, the spectrum in Figure $7(\mathrm{c})$ corresponds to a faulty gear with $75 \%$ of uniform wear; the increases in $2 f_{m}$ and $3 f_{m}$ are revealing the wear presence in the gearbox. Moreover, when $75 \%$ of uniform wear and bearing defect are mixed the fault-related frequencies have an amplitude increase as spectrum of Figure 7(d) shows; in this spectrum the wear presence is detected by the increase in their harmonics of $f_{m}$. Also the appearance of frequency components inherent to the gearbox operation is a problem for the bearing defect identification due to bearing vibrations which have lower amplitude.

Although the accelerometer sensor is placed on the top of the gearbox, bearing vibration is transmitted through the kinematic chain and acquired by the accelerometer. Aside the principal frequencies of interest, all the spectra show different frequency components that do not correspond directly to some fault-related component; the reason is that complex elements as gearboxes and bearings both linked to a kinematic chain tend to generate nonlinear vibrations [39]. Once the tests were performed, they are analyzed through vibration spectra and similar increase in the amplitude is obtained. Results are summarized numerically from Tables 2 to 7 , where tables are split up according to the operating 


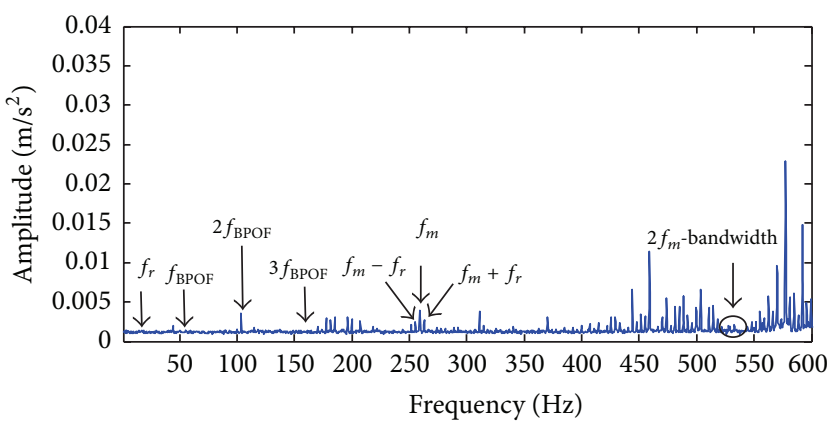

(a) Healthy condition

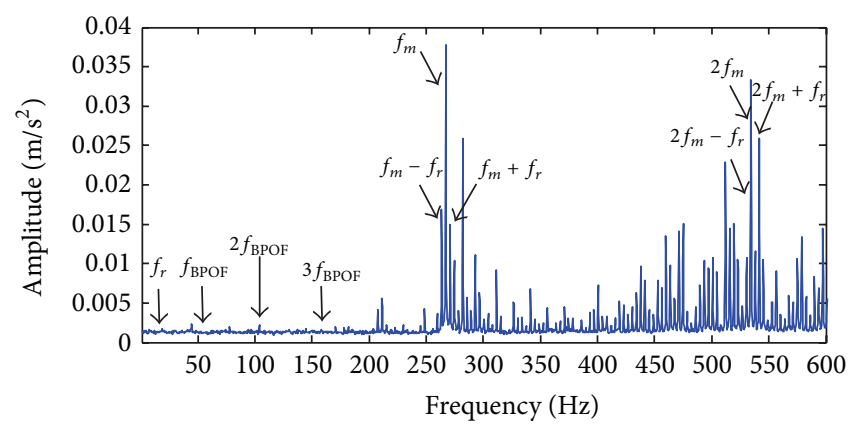

(b) $50 \%$ of uniform wear

FIgURE 6: Vibration spectra of the experiment with VFD set to $15 \mathrm{~Hz}$.

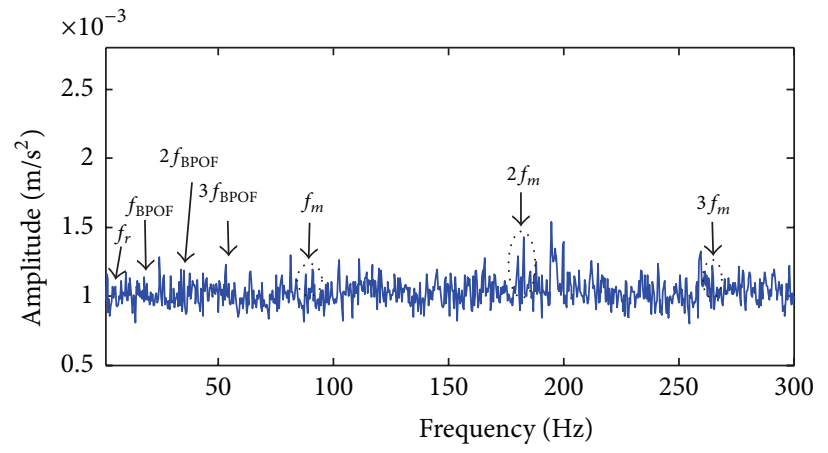

(a) Healthy condition

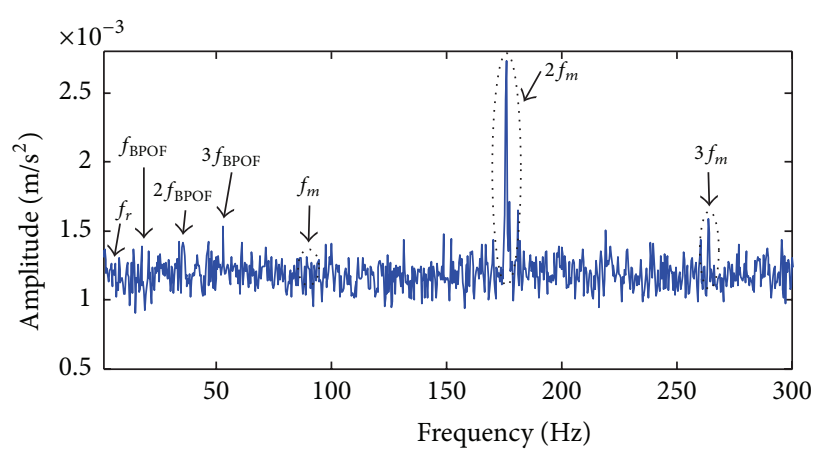

(c) $75 \%$ of uniform wear

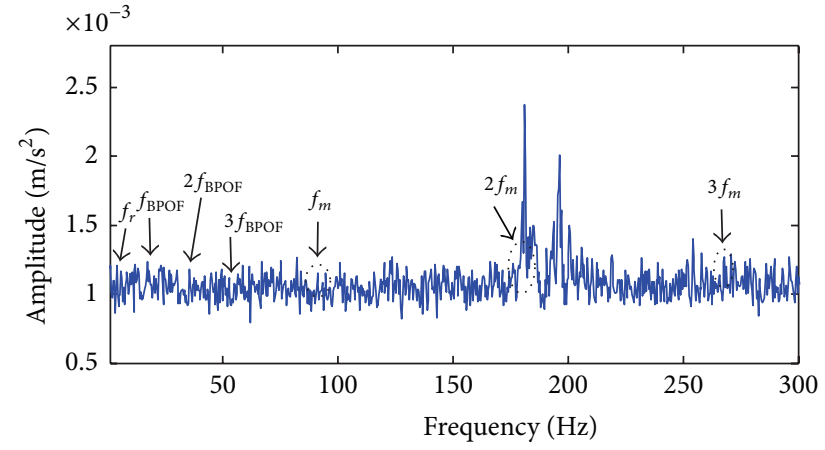

(b) Bearing defect

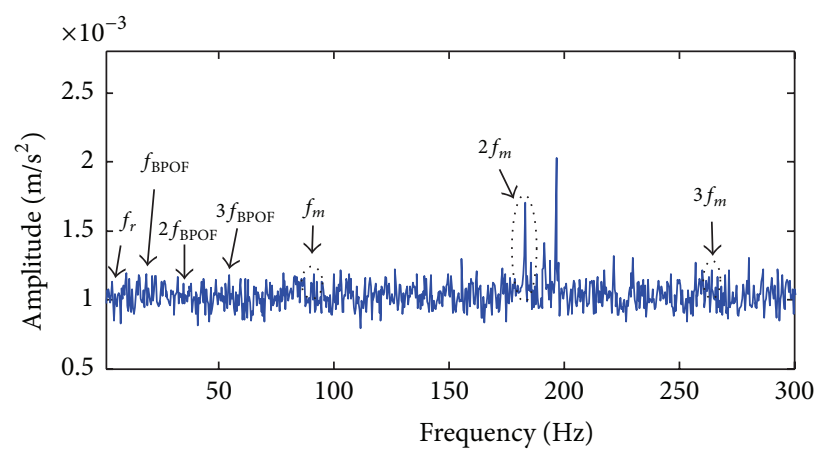

(d) $75 \%$ of uniform wear + bearing defect

FIgURE 7: Vibration spectra of the experiment with VFD set to $5 \mathrm{~Hz}$.

frequency and each one of these is divided by the bearing defect appearance.

By carrying out different experiments at different conditions and according to results, lower operating frequencies like $5 \mathrm{~Hz}$ and $15 \mathrm{~Hz}$ allow knowing gear condition by the amplitude increase in $f_{m}, 2 f_{m}$, and $3 f_{m}$ when the bearing defect is not considered, where the most significant results are given by $2 f_{m}$ amplitude increase. On the contrary, in the presence of bearing defect, the amplitude increases in $f_{m}$ and its harmonics also increase and appear in an irregular way; this phenomenon is generated by the combination and transmission of vibration through the kinematic chain. A low-level increase in amplitude is not expected in $f_{\mathrm{BPOF}}$ frequency; for this reason, the bearing defect appearance is not evident in each treated case, but sometimes it is possible to be detected by the amplitude increase in its second and third harmonics. It is clear that the bearing vibration tends to modify the behavior in the kinematic chain; furthermore, any kind of defect included in the kinematic chain adds components in the vibration spectrum.

Spectral analysis at lower operating frequencies is suitable in the detection of uniform wear in gearboxes since the quantification of the vibration levels in the frequencies of interest has a monotonic behavior, which grants the diagnosis of the levels of wear in the gearbox. In Figures 8(a)-8(c) the vibration spectra are shown for all levels of wear in the first, second, and third harmonics when the operating frequency is set to $15 \mathrm{~Hz}$ and the bearing defect is not 
TABle 2: Amplitude at the frequencies of interest for each gear condition without bearing defect and VFD set to $5 \mathrm{~Hz}$.

\begin{tabular}{lcccccc}
\hline \multirow{2}{*}{ Condition } & \multicolumn{5}{c}{ Amplitude $\left(\times 10^{-3} \mathrm{~m} / \mathrm{s}^{2}\right)$} \\
& $f_{m}$ & $2 f_{m}$ & $3 f_{m}$ & $f_{\mathrm{BPOF}}$ & $2 f_{\mathrm{BPOF}}$ & $3 f_{\mathrm{BPOF}}$ \\
\hline Healthy & 1.160 & 1.291 & 1.223 & 1.141 & 1.197 & 1.226 \\
$25 \%$ & 1.193 & 1.372 & 1.805 & 1.252 & 1.228 & 1.198 \\
$50 \%$ & 1.146 & 1.454 & 2.694 & 1.218 & 1.265 & 1.284 \\
$75 \%$ & 1.131 & 2.737 & 1.588 & 1.387 & 1.424 & 1.530 \\
\hline
\end{tabular}

TABLE 3: Amplitude at the frequencies of interest for each gear condition with bearing defect and VFD set to $5 \mathrm{~Hz}$.

\begin{tabular}{lcccccc}
\hline \multirow{2}{*}{ Condition } & \multicolumn{5}{c}{ Amplitude $\left(\times 10^{-3} \mathrm{~m} / \mathrm{s}^{2}\right)$} \\
& $f_{m}$ & $2 f_{m}$ & $3 f_{m}$ & $f_{\text {BPOF }}$ & $2 f_{\text {BPOF }}$ & $3 f_{\text {BPOF }}$ \\
\hline Healthy & 1.155 & 1.220 & 1.271 & 1.123 & 1.177 & 1.111 \\
$25 \%$ & 1.203 & 1.275 & 1.397 & 1.212 & 1.169 & 1.223 \\
$50 \%$ & 1.206 & 1.364 & 2.774 & 1.217 & 1.170 & 1.338 \\
$75 \%$ & 1.188 & 1.708 & 1.215 & 1.190 & 1.111 & 1.178 \\
\hline
\end{tabular}

TABle 4: Amplitude at the frequencies of interest for each gear condition without bearing defect and VFD set to $15 \mathrm{~Hz}$.

\begin{tabular}{lcccccc}
\hline \multirow{2}{*}{ Condition } & \multicolumn{5}{c}{ Amplitude $\left(\times 10^{-3} \mathrm{~m} / \mathrm{s}^{2}\right)$} \\
& $f_{m}$ & $2 f_{m}$ & $3 f_{m}$ & $f_{\text {BPOF }}$ & $2 f_{\text {BPOF }}$ & $3 f_{\text {BPOF }}$ \\
\hline Healthy & 3.979 & 2.095 & 6.050 & 1.182 & 1.144 & 1.305 \\
$25 \%$ & 15.96 & 7.438 & 6.821 & 1.322 & 1.178 & 1.363 \\
$50 \%$ & 37.75 & 33.31 & 28.46 & 1.347 & 1.405 & 1.347 \\
$75 \%$ & 42.29 & 34.48 & 30.09 & 1.461 & 1.322 & 1.345 \\
\hline
\end{tabular}

TABLE 5: Amplitude at the frequencies of interest for each gear condition with bearing defect and VFD set to $15 \mathrm{~Hz}$.

\begin{tabular}{lcccccc}
\hline \multirow{2}{*}{ Condition } & \multicolumn{5}{c}{ Amplitude $\left(\times 10^{-3} \mathrm{~m} / \mathrm{s}^{2}\right)$} \\
& $f_{m}$ & $2 f_{m}$ & $3 f_{m}$ & $f_{\text {BPOF }}$ & $2 f_{\text {BPOF }}$ & $3 f_{\text {BPOF }}$ \\
\hline Healthy & 2.482 & 4.673 & 8.622 & 1.204 & 1.352 & 1.427 \\
$25 \%$ & 6.522 & 6.016 & 9.611 & 1.276 & 1.381 & 1.233 \\
$50 \%$ & 13.93 & 9.154 & 13.11 & 1.432 & 1.414 & 1.427 \\
$75 \%$ & 5.154 & 6.235 & 6.344 & 1.375 & 1.284 & 1.412 \\
\hline
\end{tabular}

TABLE 6: Amplitude at the frequencies of interest for each gear condition without bearing defect and VFD set to $50 \mathrm{~Hz}$.

\begin{tabular}{lcccc}
\hline \multirow{2}{*}{ Condition } & \multicolumn{4}{c}{ Amplitude $\left(\times 10^{-3} \mathrm{~m} / \mathrm{s}^{2}\right)$} \\
& $f_{m}$ & $f_{\text {BPOF }}$ & $2 f_{\text {BPOF }}$ & $3 f_{\text {BPOF }}$ \\
\hline Healthy & 26.73 & 2.491 & 5.538 & 8.179 \\
$25 \%$ & 31.67 & 1.551 & 1.721 & 8.298 \\
$50 \%$ & 40.92 & 1.659 & 4.265 & 17.15 \\
$75 \%$ & 19.69 & 2.628 & 3.474 & 12.49 \\
\hline
\end{tabular}

present. An important part of these spectra is the amplitude increase at $f_{m}, 2 f_{m}$, and $3 f_{m}$ due to wear influence, and the difference between each one of these and their side bands is approximately $f_{r}$ of the wear with damage.

Spectral analysis at high operating frequencies somewhat limits the ability to detect faults; the disadvantage is that at
TABLE 7: Amplitude at the frequencies of interest for each gear condition with bearing defect and VFD set to $50 \mathrm{~Hz}$.

\begin{tabular}{lcccc}
\hline \multirow{2}{*}{ Condition } & \multicolumn{4}{c}{ Amplitude $\left(\times 10^{-3} \mathrm{~m} / \mathrm{s}^{2}\right)$} \\
& $f_{m}$ & $f_{\text {BPOF }}$ & $2 f_{\text {BPOF }}$ & $3 f_{\text {BPOF }}$ \\
\hline Healthy & 28.79 & 3.832 & 1.248 & 3.326 \\
$25 \%$ & 10.27 & 4.005 & 1.527 & 7.018 \\
$50 \%$ & 58.26 & 5.194 & 1.609 & 5.52 \\
$75 \%$ & 23.79 & 6.364 & 1.811 & 5.857 \\
\hline
\end{tabular}

higher operating frequencies $f_{m}$ value increases considerably and sometimes the bandwidth in the accelerometer is not enough to acquire high frequencies generated by mechanical components such as gearboxes.

Another disadvantage is that at higher operating frequencies the addition of frequency components is inherent in the kinematic chain, causing the vibration concealing related to some specific fault. Results obtained by experimental tests at $50 \mathrm{~Hz}$ of operating frequency do not allow detecting the wear appearance in the gearbox because the amplitude does not exhibit a monotonic behavior for any of the related gearbox frequencies. Also, the bearing defect is not perfectly identified through spectral analysis. Although the treated faults are not perfectly detected at higher operating frequencies, the appearance of amplitude oscillations is generated by both treated faults.

The proposed methodology involves a current analysis, in order to observe the effects caused by vibrations and to identify different behaviors related to the studied faults. In this sense, for each experiment carried out, the PSD is obtained from the motor current signals. The current analysis is mainly focused on $f_{s}$; both studied faults have influence in the motor consumption. When the experiments are carried out and the VFD is set to $5 \mathrm{~Hz}$ the current analysis lacks information connected to the studied faults. Otherwise, when the VFD is set to $15 \mathrm{~Hz}$ and $50 \mathrm{~Hz}$, by performing a current analysis, it is possible to identify changes in the PSD for each studied condition.

The studied faults have their fault-related frequencies in the vibration analysis; therefore the bearing defect has a defined effect in the motor current signal, as Section 2 describes. On the other hand, the gearbox fault presence does not have a specific effect defined; however, according to [33], the appearance of any incipient gear fault may not consistently affect the amplitude of rotating and mesh frequencies in the electrical signal but give rise to those of rotation harmonics and the lateral components appearance. Thus, in Figure 9(a) is shown the PSD for the healthy stage and all levels of uniform wear, with the VFD set to $15 \mathrm{~Hz}$ as $f_{s}$. It is possible to observe some sidebands around the central frequency; the modified behavior in each one of these sidebands is generated due to uniform wear influence. In the spectra of Figure 9(b) it is possible to observe and compare the healthy stage, bearing defect, $75 \%$ of wear, and their mixing tested at $15 \mathrm{~Hz}$ because in the presence of uniform wear when the bearing defect appears, an increase is observed in these sidebands, as well as a change in the waveform. 


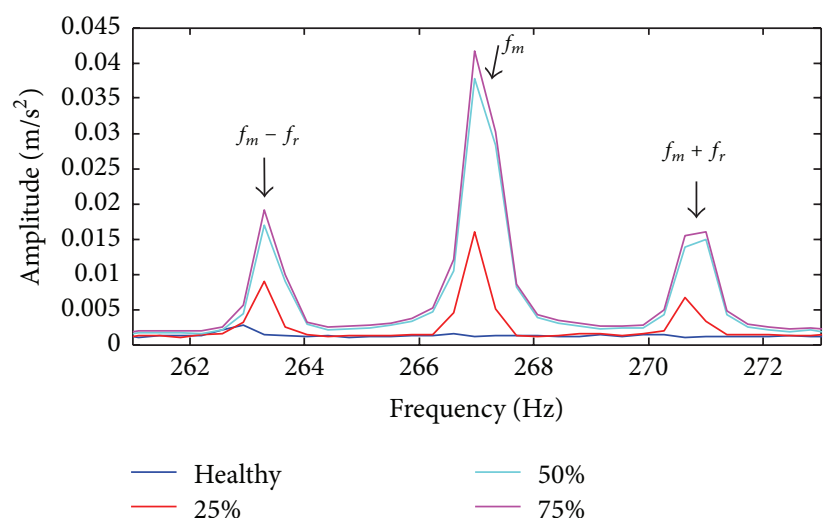

(a) First harmonic

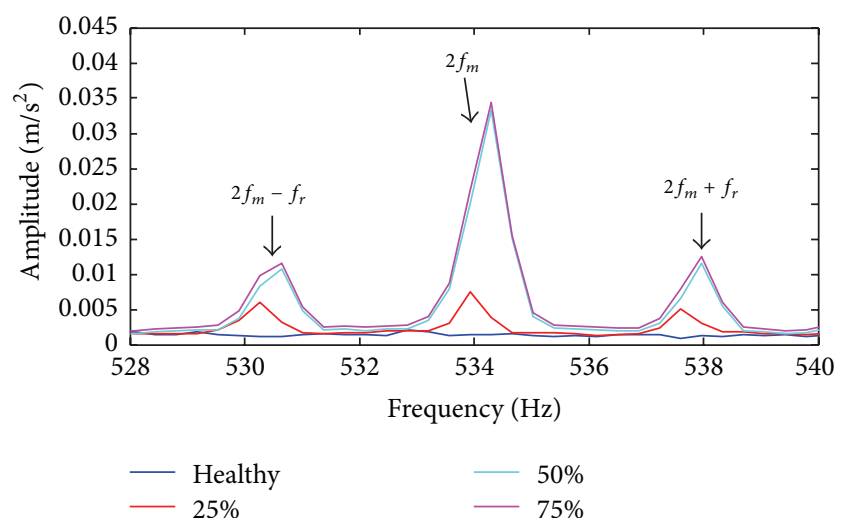

(b) Second harmonic

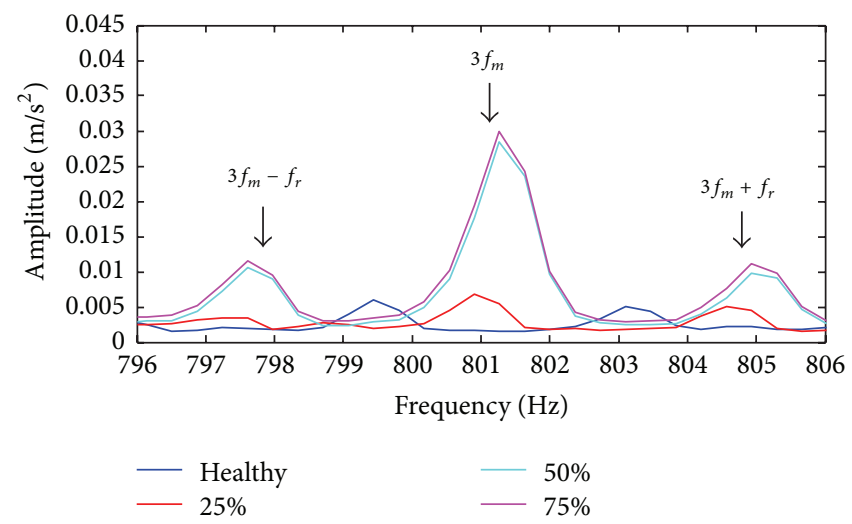

(c) Third harmonic

FIGURE 8: Vibration spectra for all gear conditions with VFD set to $15 \mathrm{~Hz}$.

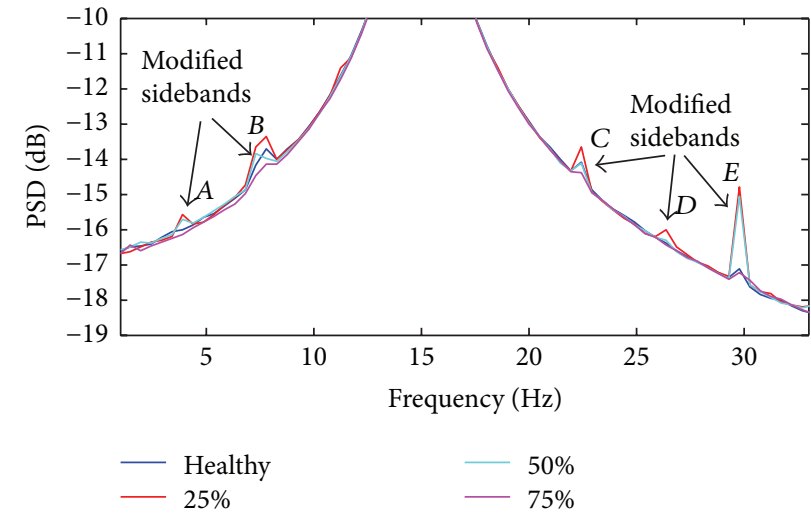

(a) For the healthy condition and all wear levels

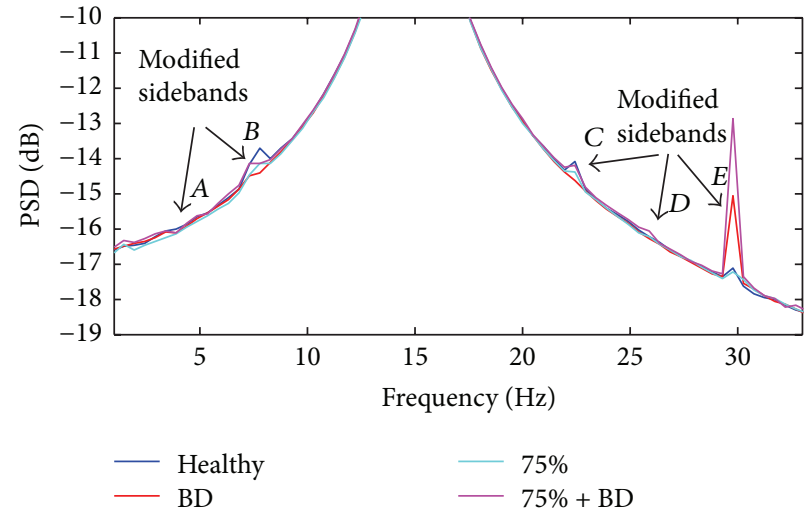

(b) For the healthy condition, bearing defect, $75 \%$ of uniform wear, and $75 \%$ of uniform wear + bearing defect

FIGURE 9: PSD spectrum from current signal when VFD is set to $15 \mathrm{~Hz}$.

The studied faults have more influence when the VFD is set to $50 \mathrm{~Hz}$; then in the spectra of Figure 10(a) the health condition and all the wear levels are shown. It is possible to notice the uniform wear effects; in these spectra the sideband frequencies appear and one of these is related to the $f_{r}$ of the worn gear; although the amplitude increase is not present in monotonic way, the amplitude modification allows knowing the presence of incipient faults as uniform wear. In spectra of Figure 10(b) the healthy condition, bearing defect, $75 \%$ of wear, and their mixing are depicted. In these spectra the bearing defect modified the amplitude in the sideband frequencies. Furthermore, by performing the current analysis in the bearing defect related frequency $f_{\mathrm{BE}}$, it is possible to detect the bearing defect; due to the direct appearance of 


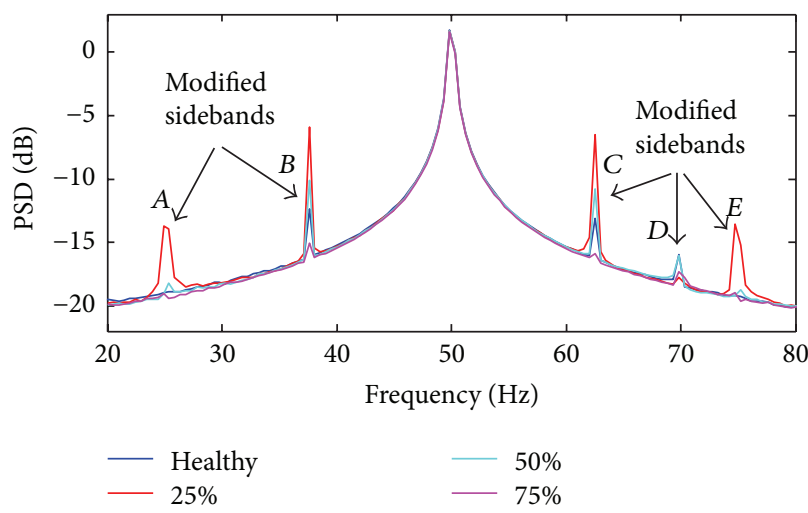

(a) For the healthy condition and all wear levels

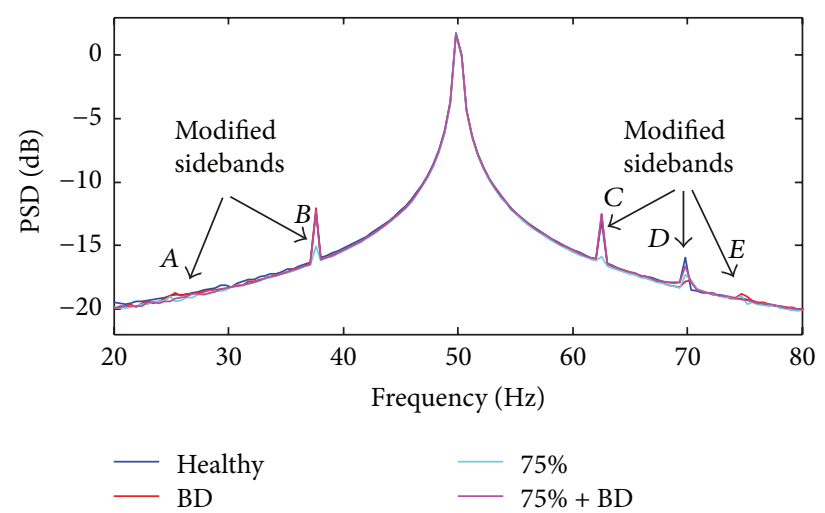

(b) For the healthy condition, bearing defect, $75 \%$ of uniform wear, and $75 \%$ of uniform wear + bearing defect

FIgURE 10: PSD spectrum from current signal when VFD is set to $50 \mathrm{~Hz}$.

TABLE 8: Principal frequency components to be analyzed in current spectra.

\begin{tabular}{lccccccc}
\hline Frequency set in & \multicolumn{8}{c}{ Frequencies around the supply frequency $(\mathrm{Hz})$} \\
VFD $(\mathrm{Hz})$ & $f_{s}$ & $A$ & $B$ & $C$ & $D$ & $E$ & $f_{\mathrm{BE}}$ \\
\hline 15 & 15.14 & 3.90 & 7.81 & 22.46 & 26.37 & 29.79 & 83.02 \\
50 & 49.81 & 25.39 & 37.60 & 62.50 & 69.82 & 74.71 & 277.64 \\
\hline
\end{tabular}

TABLE 9: Amplitude of the current analysis frequencies for each gear condition without bearing defect and VFD set to $15 \mathrm{~Hz}$.

\begin{tabular}{lccccccc}
\hline Frequency set & \multicolumn{6}{c}{ Frequencies around the supply frequency $(\mathrm{Hz})$} \\
in VFD $(\mathrm{Hz})$ & $f_{s}$ & $A$ & $B$ & $C$ & $D$ & $E$ & $f_{\mathrm{BE}}$ \\
\hline Healthy & 2.48 & -16.01 & -13.71 & -14.09 & -16.40 & -17.12 & -24.06 \\
$25 \%$ & 2.44 & -15.58 & -13.36 & -13.62 & -16.01 & -14.79 & -23.66 \\
$50 \%$ & 2.44 & -15.70 & -13.84 & -14.13 & -16.31 & -15.06 & -23.59 \\
$75 \%$ & 2.41 & -14.14 & -14.16 & -14.39 & -16.45 & -17.24 & -24.32 \\
\hline
\end{tabular}

TABLE 10: Amplitude of the current analysis frequencies for each gear condition with bearing defect and VFD set to $15 \mathrm{~Hz}$.

\begin{tabular}{lccccccc}
\hline Frequency set & \multicolumn{6}{c}{ Frequencies around the supply frequency $(\mathrm{Hz})$} \\
in VFD $(\mathrm{Hz})$ & $f_{s}$ & $A$ & $B$ & $C$ & $D$ & $E$ & $f_{\mathrm{BE}}$ \\
\hline Healthy & 2.48 & -16.12 & -14.49 & -14.63 & -16.28 & -15.08 & -23.32 \\
$25 \%$ & 2.44 & -15.80 & -13.78 & -14.09 & -16.18 & -17.36 & -22.56 \\
$50 \%$ & 2.44 & -15.53 & -13.34 & -13.40 & -15.98 & -15.93 & -21.71 \\
$75 \%$ & 2.41 & -16.11 & -14.15 & -14.20 & -16.08 & -12.87 & -23.17 \\
\hline
\end{tabular}

bearing fault in the induction motor, it is a severe problem which can modify the machine operating condition.

In order to simplify the results, the numerical location of the principal frequency components are summarized in Table 8 , in which it is possible to find $f_{s}$, five additional frequencies $(A, B, C, D, E)$, and the bearing defect related frequency $f_{\mathrm{BE}}$. And from Tables 9 to 12 the amplitudes for these frequencies are summarized.
TABLE 11: Amplitude of the current analysis frequencies for each gear condition without bearing defect and VFD set to $50 \mathrm{~Hz}$.

\begin{tabular}{lccccccc}
\hline Frequency set & \multicolumn{6}{c}{ Frequencies around the supply frequency $(\mathrm{Hz})$} \\
in VFD $(\mathrm{Hz})$ & $f_{s}$ & $A$ & $B$ & $C$ & $D$ & $E$ & $f_{\mathrm{BE}}$ \\
\hline Healthy & 1.75 & -18.86 & -12.34 & -13.13 & -15.99 & -19.16 & -28.39 \\
$25 \%$ & 1.68 & -13.93 & -5.90 & -6.50 & -17.74 & -13.59 & -27.76 \\
$50 \%$ & 1.68 & -18.22 & -10.13 & -10.76 & -16.00 & -18.73 & -27.30 \\
$75 \%$ & 1.58 & -19.40 & -15.02 & -15.9 & -17.33 & -18.97 & -27.97 \\
\hline
\end{tabular}

TABLE 12: Amplitude of the current analysis frequencies for each gear condition with bearing defect and VFD set to $50 \mathrm{~Hz}$.

\begin{tabular}{lccccccc}
\hline Frequency set & \multicolumn{6}{c}{ Frequencies around the supply frequency $(\mathrm{Hz})$} \\
in VFD $(\mathrm{Hz})$ & $f_{s}$ & $A$ & $B$ & $C$ & $D$ & $E$ & $f_{\mathrm{BE}}$ \\
\hline Healthy & 1.66 & -18.74 & -12.03 & -12.55 & -17.85 & -18.84 & -26.46 \\
$25 \%$ & 1.67 & -13.27 & -6.00 & -6.54 & -17.94 & -13.24 & -21.74 \\
$50 \%$ & 1.63 & -15.65 & -8.48 & -9.01 & -17.98 & -15.82 & -24.28 \\
$75 \%$ & 1.67 & -19.16 & -12.25 & -12.51 & -16.64 & -19.24 & -26.34 \\
\hline
\end{tabular}

For this study, it is proved that vibrations originated by mechanical faults affect the current consumption and the operating frequency is not a problem for the identification of faults. According to these results a good quantification of uniform wear in gearbox can be done by the vibration analysis focused on the gearbox frequencies given by theory; this analysis must be carried out at lower operating frequencies to ensure the detection. The detectability of uniform wear for all the experiments carried out with and without the presence of the bearing defect is around $83 \%$ through vibration analysis, and for the bearing defect detection in the presence of uniform wear comprises around 58\%. Although bearing defect is not as well detected as the uniform wear effect from vibration analysis, it is possible to observe its effects in the vibration and current spectra. In this sense, the current analysis allows knowing the bearing defect appearance in the $83 \%$ of the experiments carried out and a $66 \%$ for the uniform wear detection. Therefore, for this research, the methodology 
found upon different physical magnitudes such as vibration and stator current improves the condition monitoring in the kinematic chain; this is due to the advantages of each technique based on different physical magnitudes.

\section{Conclusions}

This work proposes a methodology based on vibration analysis and current analysis for the diagnosis of different levels of uniform wear in a gearbox and the detection of bearing defect both linked to the same kinematic chain. The methodology is based on the acquisition of vibration signals that are generated in the kinematic chain and induction motor current signals, along with an adequate signal processing to analyze the amplitude at the frequencies of interest given by theory, to provide reliable results of fault diagnosis. The vibration analysis results show that the amplitude increase in the mesh frequency component and its corresponding harmonics are related to the presence of wear in the gearbox. The analysis at lower operating frequencies perfectly detects the presence of wear in the gearbox because of the monotonic increase in all the mesh frequencies. Although at higher operating frequency it is not suitable for detecting uniform wear, it is possible to consider the nonmonotonic amplitude change in the mesh frequency as an indicator of the uniform wear presence.

As [38] mentions, the most common complex mechanical systems are gearboxes and bearings; therefore, nonlinear vibrations are inherent to their operation. For the present case, the presence of uniform wear in the gearbox and the remote location of the accelerometer make it difficult to determine perfectly the presence of the bearing defect based on the vibration analysis. Furthermore, the vibration effects on the kinematic chain are corroborated by doing the analysis to the induction motor current signals, which also detect the uniform wear effect by the sideband modification related to the rotational frequency of the worn gear, and the bearing fault presence by performing an analysis in the faultrelated frequency component associated with the vibration effect. Additionally, with this study, it is demonstrated that any modification in the kinematic chain has effects capable of modifying the operation process. Furthermore, with the acquisition of more than one physical magnitude in the condition monitoring and fault detection in rotating machinery, the detection of multiple faults can be performed with better results.

From an industrial perspective, the proposed method can be extended and improved for further development. The structure of the proposed methodology makes it suitable for online monitoring and fault detection using embedded systems such as FPGA. The hardware implementation for online operation is possible because the Hanning filters and FFT modules can be easily integrated in FPGA devices as lowcost high-performance units. Also, the use of acceleration and current signals with an automatic classification system could produce an improved methodology based on the data fusion for multiple-fault detection in kinematic chains. For further improvement of the analysis method, there are other techniques that can be used that are able to deal with nonstationary signals for analyzing the case of variable loads during operation.

\section{Competing Interests}

The authors declare that they have no competing interests.

\section{Acknowledgments}

This research was partially supported by CONACyT Scholarship 278033, FOMIX QRO-2014-C03-250269, and SEPCONACyT 222453-2013 Grants.

\section{References}

[1] G. Niu, B.-S. Yang, and M. Pecht, "Development of an optimized condition-based maintenance system by data fusion and reliability-centered maintenance," Reliability Engineering \& System Safety, vol. 95, no. 7, pp. 786-796, 2010.

[2] A. Bellini, F. Filippetti, C. Tassoni, and G.-A. Capolino, "Advances in diagnostic techniques for induction machines," IEEE Transactions on Industrial Electronics, vol. 55, no. 12, pp. 4109-4126, 2008.

[3] V. T. Tran and B.-S. Yang, "An intelligent condition-based maintenance platform for rotating machinery," Expert Systems with Applications, vol. 39, no. 3, pp. 2977-2988, 2012.

[4] M. Ayad, D. Chikouche, N. Boukazzoula, and M. Rezki, "Search of a robust defect signature in gear systems across adaptive Morlet wavelet of vibration signals," IET Signal Processing, vol. 8, no. 9, pp. 918-926, 2014.

[5] L. Frosini, C. Harlisca, and L. Szabó, "Induction machine bearing fault detection by means of statistical processing of the stray flux measurement," IEEE Transactions on Industrial Electronics, vol. 62, no. 3, pp. 1846-1854, 2015.

[6] J. Antonino-Daviu, M. Riera-Guasp, J. Pons-Llinares et al., "Detection of broken outer-cage bars for double-cage induction motors under the startup transient," IEEE Transactions on Industry Applications, vol. 48, no. 5, pp. 1539-1548, 2012.

[7] D. A. Tobon-Mejia, K. Medjaher, and N. Zerhouni, "CNC machine tools wear diagnostic and prognostic by using dynamic Bayesian networks," Mechanical Systems and Signal Processing, vol. 28, pp. 167-182, 2012.

[8] H. Henao, G.-A. Capolino, M. Fernandez-Cabanas et al., "Trends in fault diagnosis for electrical machines: a review of diagnostic techniques," IEEE Industrial Electronics Magazine, vol. 8, no. 2, pp. 31-42, 2014.

[9] P. Henríquez, J. B. Alonso, M. A. Ferrer, and C. M. Travieso, "Review of automatic fault diagnosis systems using audio and vibration signals," IEEE Transactions on Systems, Man, and Cybernetics: Systems, vol. 44, no. 5, pp. 642-652, 2014

[10] P. Bangalore and L. B. Tjernberg, "An artificial neural network approach for early fault detection of gearbox bearings," IEEE Transactions on Smart Grid, vol. 6, no. 2, pp. 980-987, 2015.

[11] V. Mien, K. Hee-Jun, and S. Kyoo-Sik, "Rolling element bearing fault diagnosis based on non-local means de-noising and empirical mode decomposition," IET Science, Measurement and Technology, vol. 8, no. 6, pp. 571-578, 2014.

[12] V. C. M. N. Leite, J. G. Borges da Silva, G. F. C. Veloso et al., "Detection of localized bearing faults in induction machines by 
spectral kurtosis and envelope analysis of stator current," IEEE Transactions on Industrial Electronics, vol. 62, no. 3, pp. 18551865, 2015.

[13] T. Wang, M. Liang, J. Li, W. Cheng, and C. Li, "Bearing fault diagnosis under unknown variable speed via gear noise cancellation and rotational order sideband identification," Mechanical Systems and Signal Processing, vol. 62-63, pp. 30-53, 2015.

[14] A. Bellini, F. Immovilli, R. Rubini, and C. Tassoni, "Diagnosis of bearing faults in induction machines by vibration or current signals: a critical comparison," in Proceedings of the IEEE Industry Applications Society Annual Meeting (IAS '08), pp. 1-8, IEEE, Edmonton, Canada, October 2008.

[15] P.-L. Zhang, B. Li, S.-S. Mi, Y.-T. Zhang, and D.-S. Liu, "Bearing fault detection using multi-scale fractal dimensions based on morphological covers," Shock and Vibration, vol. 19, no. 6, pp. 1373-1383, 2012.

[16] S. Guoji, S. McLaughlin, X. Yongcheng, and P. White, "Theoretical and experimental analysis of bispectrum of vibration signals for fault diagnosis of gears," Mechanical Systems and Signal Processing, vol. 43, no. 1-2, pp. 76-89, 2014.

[17] P. A. Delgado-Arredondo, A. Garcia-Perez, D. Morinigo-Sotelo et al., "Comparative study of time-frequency decomposition techniques for fault detection in induction motors using vibration analysis during startup transient," Shock and Vibration, vol. 2015, Article ID 708034, 14 pages, 2015.

[18] B. Trajin, J. Regnier, and J. Faucher, "Comparison between vibration and stator current analysis for the detection of bearing faults in asynchronous drives," IET Electric Power Applications, vol. 4, no. 2, pp. 90-100, 2010.

[19] K. Shin and S.-H. Lee, "Machinery fault diagnosis using twochannel analysis method based on fictitious system frequency response function," Shock and Vibration, vol. 2015, Article ID 561238, 7 pages, 2015.

[20] J.-C. Urresty, J.-R. Riba, L. Romeral, and J. A. Ortega, "Mixed resistive unbalance and winding inter-turn faults model of permanent magnet synchronous motors," Electrical Engineering, 2014.

[21] J. Uddin, M. Kang, D. V. Nguyen, and J.-M. Kim, "Reliable fault classification of induction motors using texture feature extraction and a multiclass support vector machine," Mathematical Problems in Engineering, vol. 2014, Article ID 814593, 9 pages, 2014.

[22] M. Amarnath and I. R. Praveen Krishna, "Empirical mode decomposition of acoustic signals for diagnosis of faults in gears and rolling element bearings," IET Science, Measurement and Technology, vol. 6, no. 4, pp. 279-287, 2012.

[23] R. Li and D. He, "Rotational machine health monitoring and fault detection using EMD-based acoustic emission feature quantification," IEEE Transactions on Instrumentation and Measurement, vol. 61, no. 4, pp. 990-1001, 2012.

[24] Y. Qu, D. He, J. Yoon, B. Van Hecke, E. Bechhoefer, and J. Zhu, "Gearbox tooth cut fault diagnostics using acoustic emission and vibration sensors-a comparative," Sensors, vol. 14, no. 1, pp. 1372-1393, 2014.

[25] D. P. Jena and S. N. Panigrahi, "Automatic gear and bearing fault localization using vibration and acoustic signals," Applied Acoustics, vol. 98, pp. 20-33, 2015.

[26] I. Bediaga, X. Mendizabal, A. Arnaiz, and J. Munoa, "Ball bearing damage detection using traditional signal processing algorithms," IEEE Instrumentation and Measurement Magazine, vol. 16, no. 2, pp. 20-25, 2013.
[27] R. G. Teixeira de Almeida, S. A. da Silva Vicente, and L. Rodrigues Padovese, "New technique for evaluation of global vibration levels in rolling bearings," Shock and Vibration, vol. 9, no. 4-5, pp. 225-234, 2002.

[28] A. Soualhi, K. Medjaher, and N. Zerhouni, "Bearing health monitoring based on hilbert-huang transform, support vector machine, and regression," IEEE Transactions on Instrumentation and Measurement, vol. 64, no. 1, pp. 52-62, 2015.

[29] M. Amar, I. Gondal, and C. Wilson, "Vibration spectrum imaging: a novel bearing fault classification approach," IEEE Transactions on Industrial Electronics, vol. 62, no. 1, pp. 494-502, 2015.

[30] E. T. Esfahani, S. Wang, and V. Sundararajan, "Multisensor wireless system for eccentricity and bearing fault detection in induction motors," IEEE/ASME Transactions on Mechatronics, vol. 19, no. 3, pp. 818-826, 2014.

[31] X. Zhang, J. Kang, L. Xiao, J. Zhao, and H. Teng, "A new improved kurtogram and its application to bearing fault diagnosis," Shock and Vibration, vol. 2015, Article ID 385412, 22 pages, 2015.

[32] H. Li, H. Zheng, and L. Tang, "Gear fault detection based on teager-huang transform," International Journal of Rotating Machinery, vol. 2010, Article ID 502064, 9 pages, 2010.

[33] S. Hedayati Kia, H. Henao, and G.-A. Capolino, “Trends in gear fault detection using electrical signature analysis in induction machine-based systems," in Proceedings of the IEEE Workshop on Electrical Machines Design, Control and Diagnosis (WEMDCD '15), pp. 297-303, Torino, Italy, March 2015.

[34] J. J. Saucedo-Dorantes, A. G. Garcia-Ramirez, J. C. JaureguiCorrea, R. A. Osornio-Rios, A. Garcia-Perez, and R. J. RomeroTroncoso, "Reliable methodology for gearbox wear monitoring based on vibration analysis," in Proceedings of the 40th Annual Conference of the IEEE Industrial Electronics Society (IECON '14), pp. 3381-3385, IEEE, Dallas, Tex, USA, OctoberNovermber 2014.

[35] T. Geramitcioski, L. Trajcevski, I. Vilos, and V. Mitrevski, "Early gear tooth damage diagnostic from the vibration signatures," in Proceedings of the 3rd International Conference (Power Transmissions '09), Thessaloniki, Greece, 2009.

[36] W. D. Mark, “Time-synchronous-averaging of gear-meshingvibration transducer responses for elimination of harmonic contributions from the mating gear and the gear pair," Mechanical Systems and Signal Processing, vol. 62-63, pp. 21-29, 2015.

[37] M. P. Norton and D. G. Karczub, Fundamental of Noise and Vibration Analysis for Engineers, Cambridge University Press, Cambridge, UK, 2nd edition, 2003.

[38] J. C. Jauregui-Correa and O. M. Gonzales, Mechanical Vibrations of Discontinuous Systems, Nova Science, New York, NY, USA, 1st edition, 2009.

[39] J. C. Jauregui-Correa, "The effect of nonlinear traveling waves on rotating machinery," Mechanical Systems and Signal Processing, vol. 39, no. 1-2, pp. 129-142, 2013.

[40] J. A. Vite-Frias, R. D. J. Romero-Troncoso, and A. OrdazMoreno, "VHDL core for 1024-point radix-4 FFT computation," in proceedings of the IEEE International Conference on Reconfigurable Computing and FPGAs (RECONFIG '05), Puebla, Mexico, September 2005.

[41] J. D. J. Rangel-Magdaleno, R. D. J. Romero-Troncoso, R. A. Osornio-Rios, E. Cabal-Yepez, and A. Dominguez-Gonzalez, "FPGA-based vibration analyzer for continuous CNC machinery monitoring with fused FFT-DWT signal processing," IEEE Transactions on Instrumentation and Measurement, vol. 59, no. 12, pp. 3184-3194, 2010. 


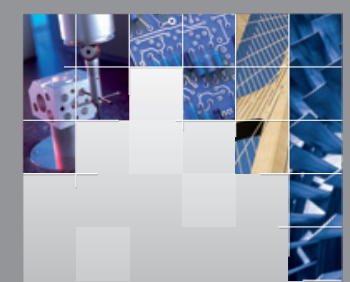

\section{Enfincering}
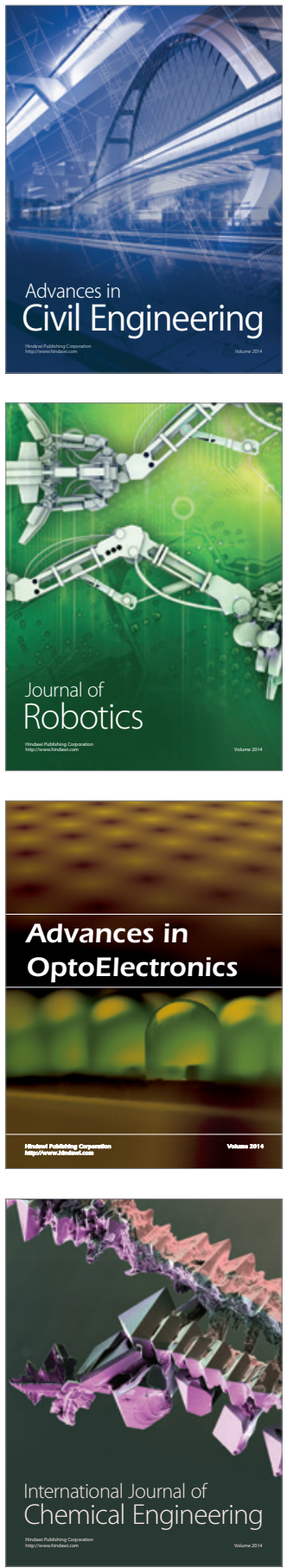

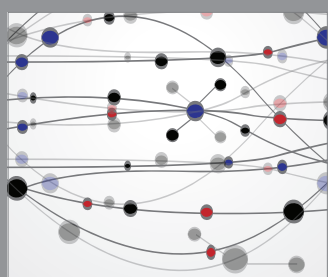

The Scientific World Journal

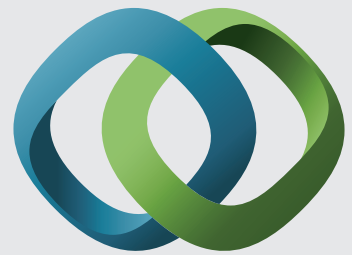

\section{Hindawi}

Submit your manuscripts at

http://www.hindawi.com
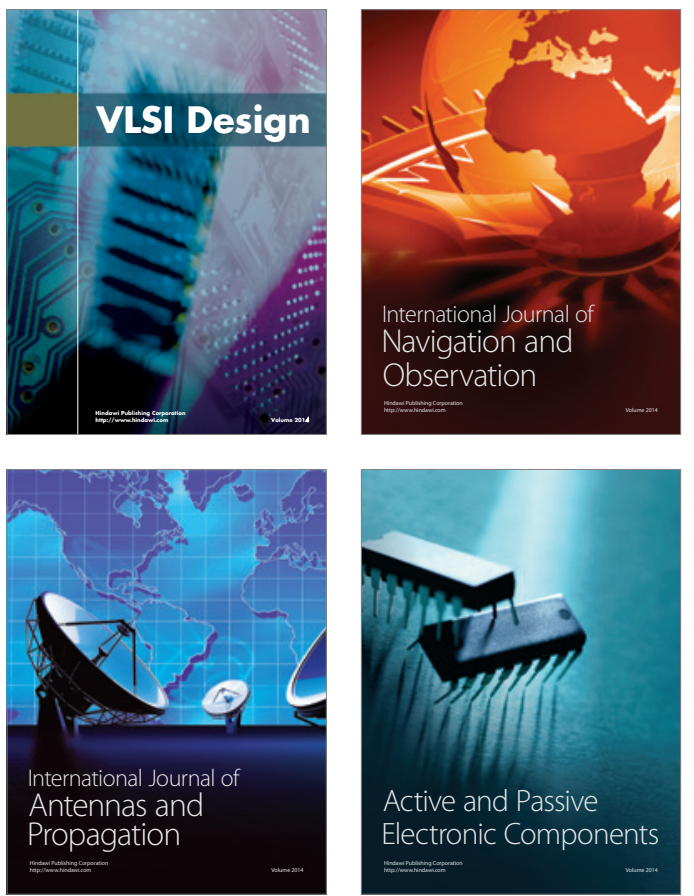
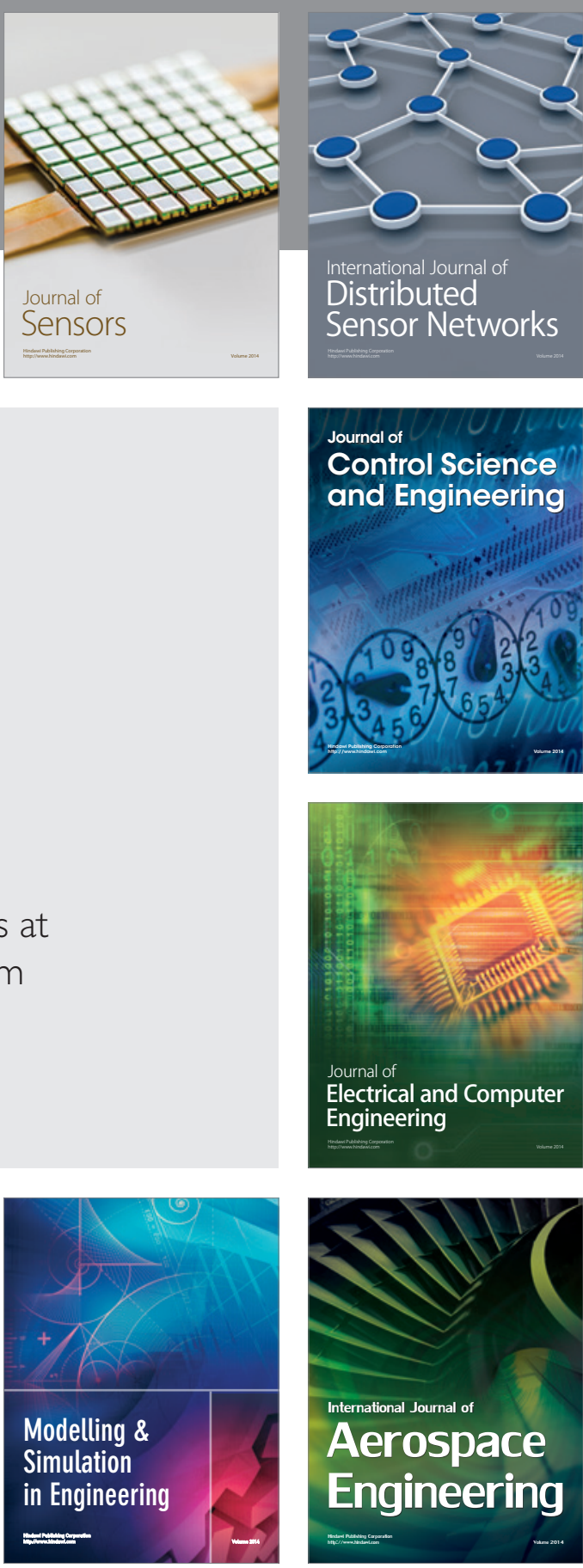

International Journal of

Distributed

Sensor Networks

Journal of

Control Science

and Engineering
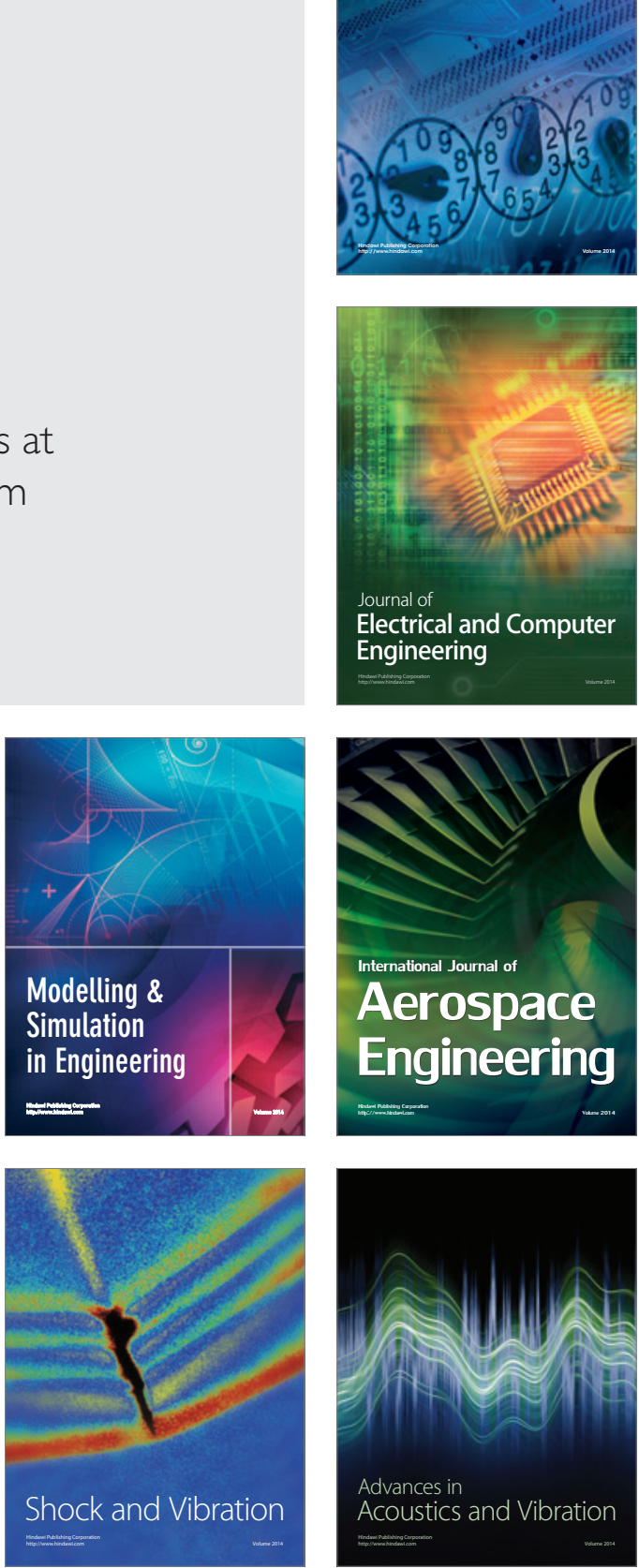